\title{
CUSTÓDIO, P. P. Alexandre Magno: aspectos de um mito de longa duração. São Paulo Annablume, 2006.
}

Thiago do Amaral Biazotto ${ }^{1}$

"Seu nome assinala o fim de uma época e o começa de uma nova" Johann Gustav Droysen (Droysen, 2010: 37).

A máxima do historiador alemão Johann Gustav Droysen sobre Alexandre, o Grande, bem ilustra a magnitude em torno da figura do conquistador macedônico. Desde contemporâneos como Cúrcio e Arriano, passando por acadêmicos como o próprio Droysen no século XIX, e chegando aos dias atuais com a obra resenhada, muitos tentaram compreender como apenas uma pessoa conseguiu feitos tão soberbos que assumiram contornos lendários.

O gênio militar. O líder nato. O piedoso com os derrotados. Mas, também, o soberbo. Aquele que se entregou às opulências orientais, que ultrapassou os seres mitológicos.

As lendas em torno de Alexandre são infindáveis e recriadas em consonância com a época que as traz à tona ${ }^{2}$. A obra

\footnotetext{
${ }^{1}$ Graduando em História pela Universidade Estadual de Campinas. Bolsista de Iniciação Científica do CNPq.

${ }^{2}$ Segundo o próprio Pedro Custódio, tais lendas são recontadas: "assumindo feições diversas de acordo com o momento de sua reaparição" (Custódio, 2006: 19).
} 
"Alexandre Magno: aspectos de um mito de longa duração", de Pedro Prado Custódio, toma a assertiva acima como base para analisar as interpretações em torno do filho de Felipe da Macedônia durante o Medievo, a partir do poema Roman d'Alexandre - na versão compilada de Alexandre de Paris - e datada de cerca de 1180-1189.

Pedro Prado Custódio possui formação em História pela Pontifícia Universidade Católica de São Paulo, doutorado em História Social pela Universidade de São Paulo com a tese "As Múltiplas Facetas de Alexandre Magno no Roman d'Alexandre" e é membro da Associação Brasileira de Estudos Medievais. Como é dedutível, sua especialização faz com que o livro adquira matizes mais medievais do que Antigas, ou seja, seu objetivo precípuo não é descrever Alexandre em sua contemporaneidade e sim suas interpretações no Mundo Medieval e a forma como seus mitos adquiriram uma tintura da época: "O passado evocado no Roman d'Alexandre é mais uma representação idealizada e moralizante do presente (século XII)" (Custódio, 2006: 25). Portanto, Custódio enumera quatro das principais facetas alexandrinas e que dão os títulos para os eixos temáticos de sua obra: "Alexandre como soberano/suserano", "Alexandre como desbravador/cruzado", "Alexandre como messias/herói mítico", "Alexandre como um rei orgulhoso: presunção e castigo?" Todos estes tropos estão 
representados no Roman d'Alexandre e têm a intenção primordial de apresentar Alexandre como modelo ideal para a incipiente ordem cavaleiresca.

O capítulo "Alexandre como soberano/suserano" se inicia com uma salutar descrição do surgimento de uma literatura vernácula, voltada aos ignorantes em latim, em concomitância com o nascer da ordem supramencionada. Estes dois elementos se unem no Roman d'Alexandre - escrito em francês - e explicam alguns dos porquês de a obra ter desfrutado de grande penetração entre a alta e baixa nobreza e a nascente burguesia. Nesta primeira representação, Alexandre é descrito como um cavaleiro ideal: corajoso, leal, justo, generoso com seus pares e clemente com os vencidos (Custódio, 2006: 27). Ademais, é o precisar lembrar que a figura alexandrina também: "representa os interesses da nobreza em processo de fusão com a cavalaria, buscando sustentação ideológica para sua existência e demonstra muita preocupação com as alterações políticas e sócio-econômicas em curso, temerosa de ter seu status quo ameaçado" (Custódio, 2006: 37).

A partir destas elucubrações, pode-se aferir que havia um norte definido para a reconstrução do conquistador macedônico: a idealização do cavaleiro medieval, dotado de virtudes irrefragáveis, e que tinha suas raízes fincadas no Mundo Antigo. Eis a longa duração, e que possuía, não obstante, devires da burguesia e 
nobreza medievais. Isto leva à outra das facetas presente no Roman d'Alexandre: a de senhor feudal, por conta da capacidade de Alexandre em equilibrar forças antagônicas e interesses dissonantes dentro de seus domínios (Custódio, 2006: 57). Sendo assim, Alexandre é, a um só tempo, cavaleiro e nobre ${ }^{3}$.

No eixo "Alexandre como desbravador/cruzado", Custódio apresenta a fisionomia do filho de Olímpia como "campeão de Deus" (Custódio, 2006: 31). Partindo do pressuposto que o Mundo Medieval era marcado pela belicosidade e a pujança das práticas religiosas - que se uniram em eventos como as Cruzadas e a Inquisição - Custódio argumenta que: "No Roman d'Alexandre, ele (Alexandre) representa um cristão lutando contra inimigos identificados com muçulmanos, demônios, povos diabólicos do Gog e Magog e com o Anticristo" (Custódio, 2006: 99). Contudo, as associações entre Alexandre e os cruzados possuíam um viés idiossincrático: elas o apresentam mais como um desbravador que ruma ao desconhecido do que como um "missionário" que carrega o estandarte de sua fé, mesmo porque o macedônico não era cristão: "as viagens de Alexandre, no âmbito do cristianismo medieval, podem ser entendidas como peregrinações religiosas em busca de

\footnotetext{
${ }^{3}$ A seguinte citação ilustra bem este viés: "Cavalaria e nobreza têm seus antagonismos escamoteados e harmonizam-se mediante a sublimação dos interesses divergentes" (Custódio, 2006: 41)
} 
algum tipo de manifestação divina. Seriam como um sacrifício, uma penitência em troca de salvação" (Custódio, 2006: 132).

Destarte, chega-se a mais um dos apanágios do Roman d'Alexandre: uma tentativa de "cristianizar" seu protagonista, notadamente pagão, com o objetivo de aproximá-lo da realidade medieval.

O próximo tópico da obra é "Alexandre como messias/herói mítico". Segundo o autor, a figura do herói místico é um processo de longuíssima duração, presente em diversas culturas e épocas e que possuía características como a capacidade de rechaçar a ameaça dos povos estrangeiros, repelir a anarquia interna e afastar as catástrofes naturais (Custódio, 2006: 151). Mas, neste caso do Roman d'Alexandre, houve uma readaptação destes ditames à realidade cristã e medieval, de forma que Alexandre apresenta uma ambigüidade em torno de sua origem, fruto de pais humanos e divinos - do ponto de vista do mito, - e que, por fim, acabam por impedi-lo de chegar à sonhada imortalidade (Custódio, 2006: 159).

A lenda do bravio herói e redentor de um povo é recontada mais uma vez, contudo, com um final diferente: "No momento em que Roman d'Alexandre foi produzido buscava-se um denominador comum que unisse as diversas camadas sociais que compunham a cavalaria, e havia também a pretensão de conter o avanço da burguesia ascendente, ameaçadora dos privilégios feudais. Por esse 
Cadernos de Clio, Curitiba, n. ${ }^{\circ}$ 3, 2012

motivo, um herói já mitificado como Alexandre foi adaptado ao contexto da época e transformado no soberano e cavaleiro ideal" (Custódio, 2006: 161).

O último dos capítulos principais, "Alexandre como um rei orgulhoso: presunção e castigo?", é também o mais exíguo, por se tratar de um sutil traço do conquistador macedônico. Nele, Custódio retoma as formas através das quais as antigas interpretações de um Alexandre desregrado, soberbo por suas conquistas militares, de atos intempestivos regados a vinho, adquiriram um certo verniz moralizante no poema do século XII. Nele, a grandeza dos feitos de um homem nunca deve se dissociar da parcimônia de seus atos.

Alexandre não seguiu este conselho e foi vítima do mais hediondo dos crimes para a sociedade medieval: a traição. Não apenas isso: os traidores - Antipater e Divinuspater - só levaram o crime a cabo por estarem sob os entorpecentes efeitos do vinho, em mais uma das opulentas celebrações daquele que se proclamou descendente do próprio Dionísio. A mensagem é clara: a grandeza de um homem não está apenas em seus atos e conquistas. Está em sua altivez. À glória da imortalidade só estão destinados aqueles de caráter inflexível. Em suma, Alexandre era: "um herói que encarna virtudes cavaleirescas e até messiânicas, mas que perdeu tudo por causa de seu orgulho e ambição, sendo punido com uma morte trágica e precoce" (Custódio, 2006: 231) 
"Alexandre Magno: aspectos de um mito de longa duração" se encerra com a redescoberta do conquistador macedônico em épocas modernas, nas quais adquiriu contornos que vão do monarca absolutista (Custódio, 2006: 235) ao super-homem nietzschiano (Custódio, 2006: 236). Neste ponto se encontra um dos grandes méritos do livro de Custódio: a sugestão para pesquisas que tomem estas redescobertas com objeto de estudo. Sabe-se que toda história, quando (re)contada adquire vieses dos períodos contemporâneos. Não foi diferente com as lendas em torno do arauto do Helenismo durante o Medievo. Alexandre é uma criatura de quatro faces: suserano, cruzado, herói mítico e até mesmo rei orgulhoso. Entretanto, estas quatro faces se encontram e se harmonizam no ideal do cavaleiro medieval: ele é justo, leal com seus pares, piedoso com os inimigos, defensor de sua fé, desbravador dos mais longínquos rincões, redentor de um povo e paladino da paz, de modo que sua feição adquire traços de herói místico. Contudo, as virtudes supracitadas de nada adiantam quando não estão na presença da sobriedade e da parcimônia. Aquele que ignorar este alerta encontrará uma morte precoce. O Roman d'Alexandre é, pois, um manual de cavalaria. Afinal: "a literatura cavaleiresca é mais prescritiva do que descritiva" (Custódio, 2006: 43). 
Concluí-se que Pedro Prado Custódio apresenta uma obra sobremodo pertinente, de boa leitura, grande erudição - os trechos citados do Roman d'Alexandre em francês são traduzidos pelo autor - e densidade, em particular no que diz respeito às muitas fábulas de Alexandre em outras partes do mundo, mencionadas diversas vezes. Além de servir como modelo e base para outras pesquisas que trabalhem com a mitificação de Alexandre em determinado recorte temporal, os escritos de Custódio nos recordam de algo que o historiador jamais pode se esquecer: o passado é construído de acordo com os interesses do presente. Descobrir quais são tais interesses é nosso papel e missão fundamentais.

\section{Agradecimentos}

Agradeço meu orientador, Prof. Pedro Paulo Abreu Funari, pelo apoio acadêmico e pelos comentários feitos a respeito deste texto. Menciono, também, o suporte financeiro do CNPq em minha pesquisa de Iniciação Cientifica. As idéias apresentadas são de minha responsabilidade. 
Cadernos de Clio, Curitiba, n. ${ }^{\text {o } 3,} 2012$

\section{Referências bibliográficas:}

CUSTÓDIO, P. P. Alexandre Magno: aspectos de um mito de longa duração. São Paulo Annablume, 2006.

DROYSEN, J. G. Alexandre o Grande. Rio de Janeiro: Contraponto, 2010. 